\title{
Vitamin D deficiency: a concern in pregnant Asian women
}

\author{
BY MAZIN ALFAHAM ${ }^{*}$, STUART WOODHEAD ${ }^{2}$, GUNILLA PASK ${ }^{1}$ \\ AND DAVID DAVIES ${ }^{\mathfrak{1}}$ \\ Departments of ${ }^{1}$ Child Health and ${ }^{2}$ Medical Biochemistry, University of Wales College of \\ Medicine, Heath Park, Cardiff CF4 4XW
}

(Received 31 May 1994 - Revised 26 September 1994 -Accepted 31 October 1994)

\begin{abstract}
Vitamin D status of Asian mothers in Cardiff was investigated during early pregnancy and at the time of the birth of their babies, using serum parathyroid hormone (PTH). Median values in Asian ( $n$ 32) and Caucasian $(n$ 63) mothers in early pregnancy were 1.56 and 0.81 pmol/1 respectively. PTH levels from a separate sample of nineteen Asian and twenty-five Caucasian mothers at the time of birth were 3.0 and 2.20 pmol/I respectively. Altogether twelve Asian and two Caucasian women had elevated PTH. All Asian women who had high PTH values also had a very low serum 25-hydroxycholecalciferol level (250HD). All samples were taken from women with no significant medical history and normal obstetric history. These findings suggest that subclinical vitamin $\mathbf{D}$ deficiency is still a cause for concern in Asian women. More active measures need to be taken to implement current recommendations to improve their vitamin $\mathbf{D}$ intake in pregnancy.
\end{abstract}

Parathyroid hormone: Vitamin D: Pregnancy

Vitamin D deficiency can occur whenever the demand for the vitamin exceeds supply, as in periods of rapid growth in fetal life, infancy, early childhood and puberty and during pregnancy, lactation and in the elderly. It was the vulnerability of the growing child to rickets that prompted, in the 1940s, fortification of certain foods with vitamin D with or without $\mathrm{Ca}$, and supplements in the form of cod-liver oil being made available free of charge. Tablets which contained vitamins $\mathrm{A}$ and $\mathrm{D}, \mathrm{Ca}_{3}\left(\mathrm{PO}_{4}\right)_{2}$ and $\mathrm{KI}$ were provided free for all mothers during pregnancy and for 30 weeks after delivery. Yet in spite of these measures a small number of cases continued to occur among British infants and young children living in poor social conditions where mothers failed to appreciate the need for vitamin supplements, and when household milk containing small amounts of vitamin D was offered as a substitute for human milk or fortified artificial milks (Department of Health and Social Security, 1980). However, since the early 1960 s nutritional rickets has been identified mostly, but not exclusively, in immigrant families, mainly Asians. Prevalences of biochemical and clinical rickets in Glasgow's Asian children of 50 and 5\% respectively were reported in the 1960s and 1970s (Ford et al. 1972; Goel et al. 1976). In Birmingham in the mid 1980s, $40 \%$ of 145 Asian toddlers aged 22 months had low serum vitamin D levels (Grindulis et al. 1986). Osteomalacia has been reported also in Asian women of child-bearing age who had lived for some years in Britain (Stamp et al. 1980) including those who were pregnant (Holmes et al. 1973). Brooke et al. (1980) in a study of vitamin D supplements in pregnant Asian women living in London showed a high incidence of vitamin $\mathrm{D}$ deficiency during the last trimester; $37 \%$ of 126 women had 25 hydroxycholecalciferol (25OHD) concentrations below $4 \mathrm{ng} / \mathrm{ml}$ at $28-32$ weeks gestation.

* Present address: Department of Child Health, Llandough Hospital NHS Trust, Penarth, Cardiff, South Glamorgan CF64 2XX. 
By term sixty-seven of these 126 women had not been given vitamin supplements; $53 \%$ had levels of $250 \mathrm{OHD}$ below $4 \mathrm{ng} / \mathrm{ml}$. In their study sustained plasma $250 \mathrm{OD}$ concentrations below $4 \mathrm{ng} / \mathrm{ml}$ were associated with osteomalacia. Heckmatt et al. (1979) measured plasma $250 H D$ concentrations during the first day of the puerperium and found $81 \%$ of forty-four Asian mothers to have levels in the osteomalacic range. However, none of the mothers had clinically detectable osteomalacia, which confirms the general impression that such deficiencies, being borderline or mild, can remain undetected for a long time, although the effect on the health status of the mother and her baby in the long term has not been evaluated. Neonatal rickets in two Asian babies has been described in association with maternal vitamin D deficiency (Ford et al. 1973). Fetal rickets has been reported in a Pakistani woman in Manchester (Russell \& Hill, 1974). Several sporadic cases of rickets in infants of Asian or Middle Eastern origin have been encountered in Cardiff in the last 6 years.

Measurement of circulating $250 \mathrm{HD}$ has been used as a definitive index of vitamin D status in the majority of published studies, although the complexity of existing analytical methods precludes its routine use as a screening test. However, since secondary hyperparathyroidism is an inevitable consequence of vitamin D deficiency, the availability of simple, sensitive assays of circulating parathyroid hormone (PTH) offers an indirect but effective means of screening populations at risk (Brown \& Woodhead, 1992). This investigation reports the vitamin D status of Asian mothers in Cardiff in the early 1990s. Its findings suggest that subclinical vitamin $\mathrm{D}$ deficiency, probably from dietary inadequacy and/or lack of exposure to sunlight, is still a problem that needs to be targeted.

\section{METHODS \\ Patients and blood samples}

Surplus blood from blood samples taken during early pregnancy (at the time of the first antenatal visit which is usually achieved at approximately 12-16 weeks) for estimating $\alpha$ feto-protein was taken from thirty-two Asian women and sixty-three Caucasian women.

Blood samples were also taken from a different group of mothers at the time of birth of their baby, nineteen Asians and twenty-five Caucasians. All mothers were in good health and deliveries were normal. The following information was noted: past medical history, parity, type of diet, occupation and ability to communicate in English with the investigator.

Ethical approval was obtained from the local Ethical Committee.

\section{Measurement of parathyroid hormone}

Intact PTH was measured by immunochemiluminometric assay (Magic Lite; Ciba Corning Diagnostics, Halstead, Essex). The adult reference range for non-pregnant individuals is $0.8-5.4 \mathrm{pmol} / 1$ (Turner et al. 1991). However, in view of a previous study (Davis et al. 1988) which showed reduced levels of PTH in pregnant women, a cut-off of 4 pmol/1 was selected as the upper reference value in our investigation. All samples that yielded high PTH had 25OHD estimated by competitive-protein-binding assay following sample extraction (Medgenix Diagnostics, 6220-Fleurus, Belgium). The reference for normal adults is $8-50 \mathrm{ng} / \mathrm{ml}$ (Turner et al. 1991).

\section{Statistical analysis}

Comparisons between group means were made using the Mann-Whitney test. Data are expressed as medians.

\section{RESULTS}

Fig. 1 shows the results of PTH concentration in early pregnancy for a sample of thirtytwo Asian and sixty-three Caucasian women. The serum samples of the Caucasian women 


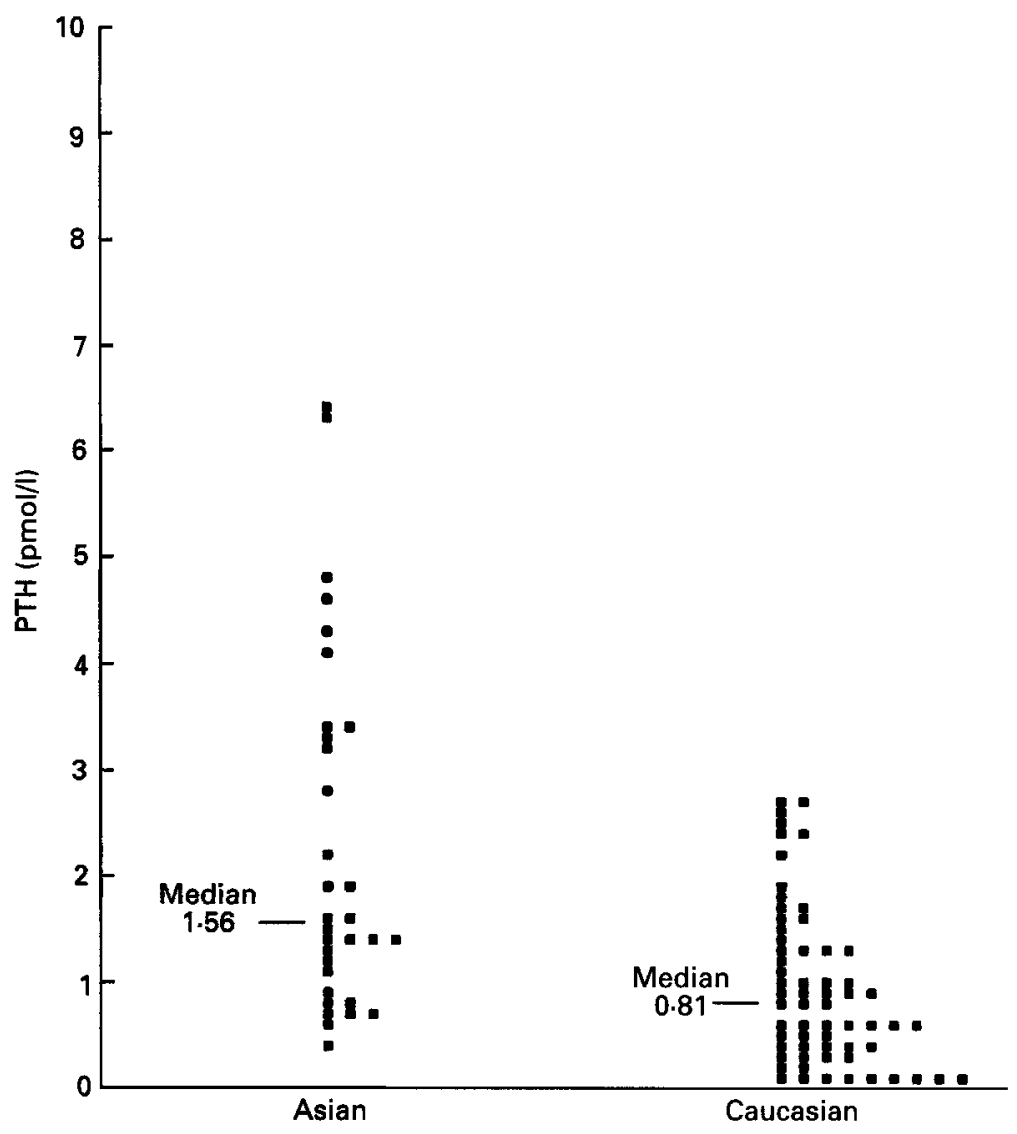

Fig. 1. Parathyroid hormone (PTH) levels in thirty-two Asian and sixty-three Caucasian women during early pregnancy. For details of subjects and procedures, see p. 882 .

show a median value of $0.81 \mathrm{pmol} / 1$. In agreement with previous work, the observed levels are somewhat lower than those seen in normal adult populations (Davis et al. 1988). The PTH concentrations found in thirty-two Asian women were significantly higher, the median being $1.56 \mathrm{pmol} / 1$. The statistical tests for the samples of Asian and Caucasian women in early pregnancy show that there is a significant difference between the two samples $(P=0.0001$; Mann-Whitney test $)$.

Samples taken at the time of birth from twenty-five Caucasian and nineteen Asian mothers showed similar differences, as shown in Fig. 2. The median for Caucasian women was $2.20 \mathrm{pmol} / \mathrm{l}$, and that for Asian women was $3.0 \mathrm{pmol} / 1$. The statistical tests for the samples of Asian and Caucasian women at time of birth show that there is a significant difference between the two samples ( $P=0.04$ Mann-Whitney test).

Altogether twelve Asian women had PTH in excess of $4 \mathrm{pmol} / 1$; measurement of 25OHD was possible only in nine women. All $250 H D$ values were below the lower reference interval for this test $(8 \mathrm{ng} / \mathrm{ml})$ with four values being below $1.0 \mathrm{ng} / \mathrm{ml}$, as shown in Fig. 3. Two Caucasian women had levels of PTH in excess of 4 pmol/1. Their 25OHD was within the normal range.

For mothers who were studied at the time of birth there was no discernible clinical difference between those Asian mothers with high PTH and reduced 25OHD $(n 6)$ and the remainder of the Asian women ( $n 13$ ), although it was noted that most of the former group 


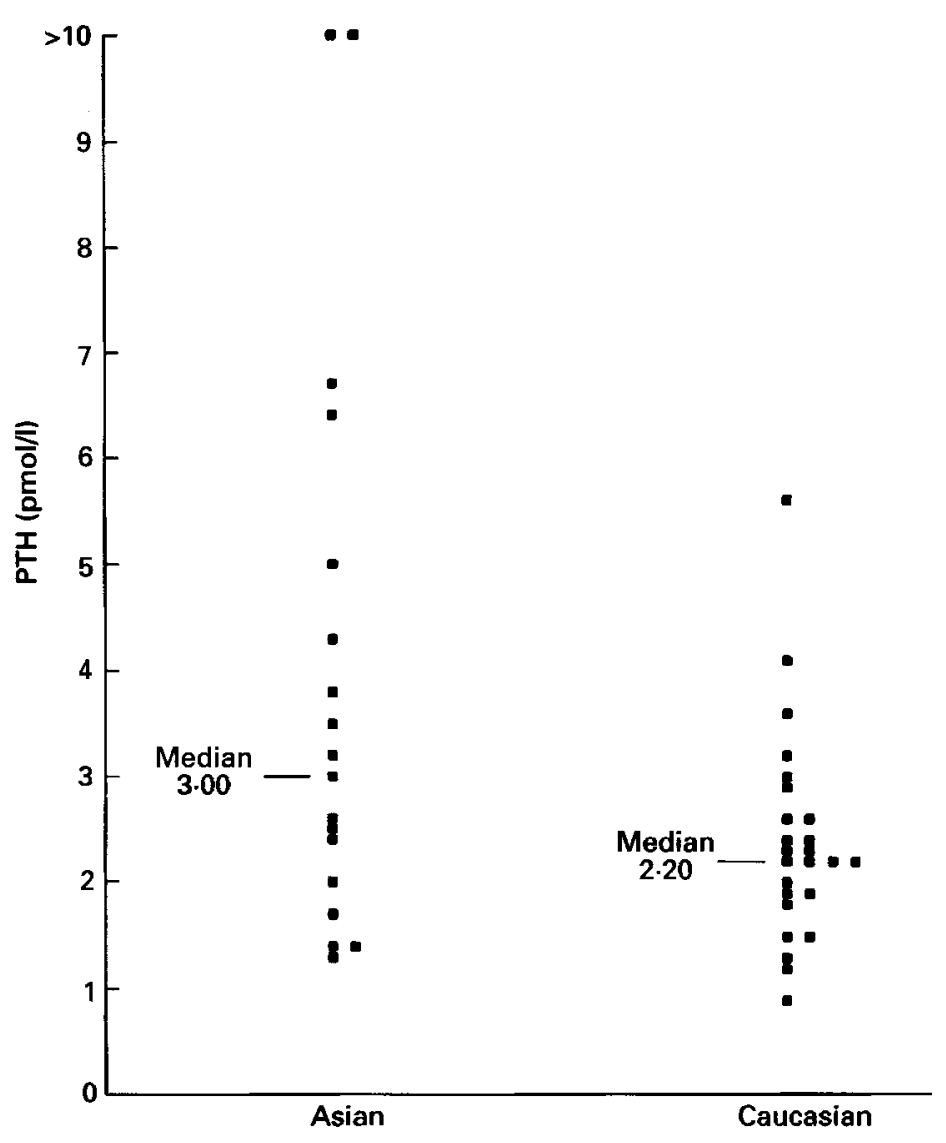

Fig. 2. Parathyroid hormone (PTH) levels of nineteen Asian and twenty-five Caucasian mothers at birth. For details of subjects and procedures, see p. 882 .

had some difficulty in communicating in English. A summary of the comparison between the two groups is shown in Table 1.

\section{DISCUSSION}

These findings indicate that there could be a significant number of Asian women in Cardiff subclinically deficient in vitamin $D$.

Several factors predispose some of the Asian minority groups in Britain to vitamin D deficiency, the most notable being lack of exposure to sunlight, excess clothing and different dietary practices (Deparment of Health and Social Security, 1980). To prevent vitamin D deficiency in the Asian immigrant population the Department of Health and Social Security in 1981 recommended: $(a)$ the use of certain fortified foods such as margarine; $(b)$ for those responsible for the health of Asian members of the population, priority should be given to the education of health professionals and the Asian immigrants themselves about the importance of vitamin D for health, including the need for out-of-doors exposure to sunlight; $(c)$ the provision under the welfare food scheme of vitamin supplements which contain vitamin $\mathrm{D}$, children's vitamin drops for children up to the age of 5 years and vitamin tablets for expectant and nursing mothers for 30 weeks after delivery. 


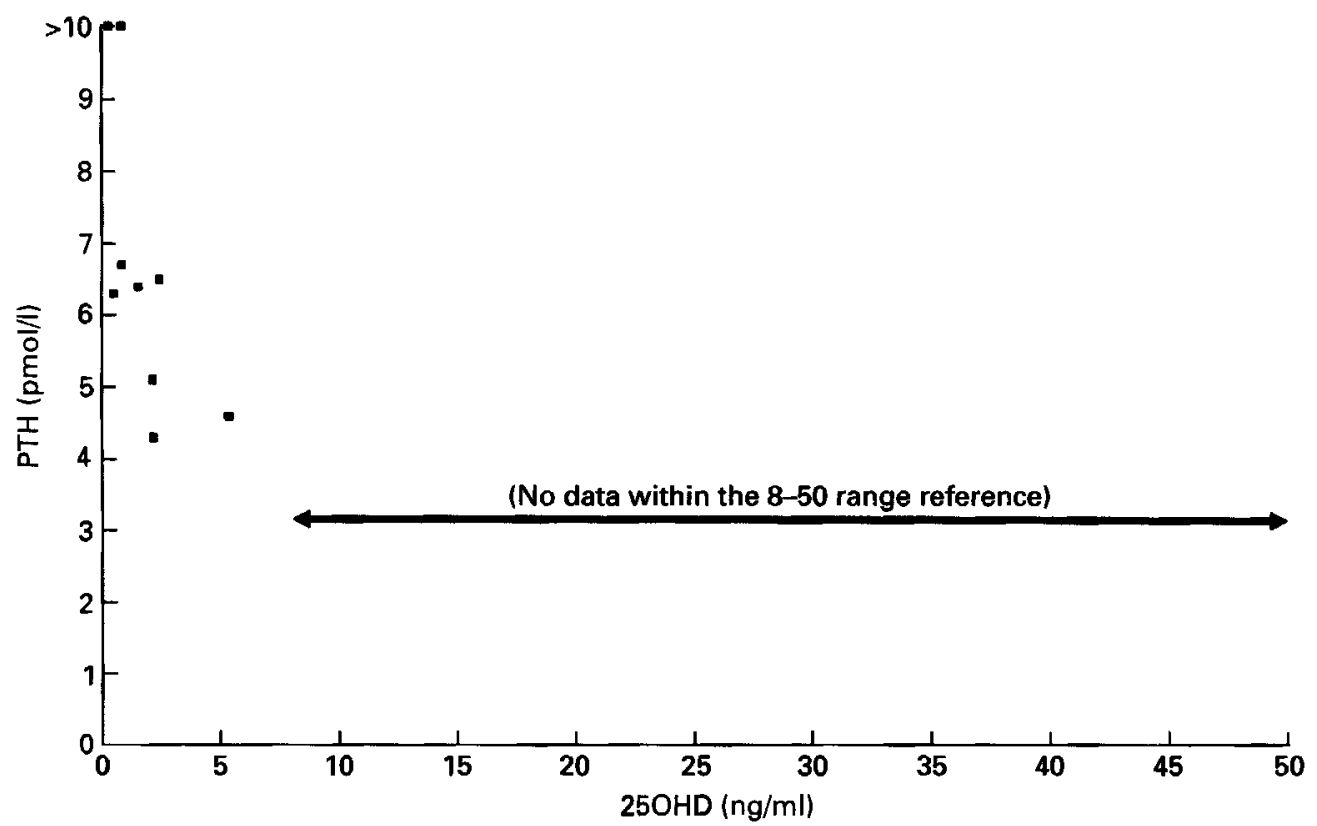

Fig. 3. Serum 25-hydroxycholecalciferol (25OHD) and parathyroid hormone (PTH) levels in nine Asian women. For details of subjects and procedures, see p. 882.

Table 1. A comparison of two groups of Asian women with high or normal serum parathyroid hormone (PTH) levels*

\begin{tabular}{|c|c|c|c|}
\hline & & $\begin{array}{c}\text { High PTH, } \\
\text { low 25OHD } \\
(n 6)\end{array}$ & $\begin{array}{c}\text { Normal } \\
\text { PTH } \\
(n \text { 13) }\end{array}$ \\
\hline \multicolumn{2}{|c|}{ Past medical history } & Healthy & Healthy \\
\hline \multirow{2}{*}{ Parity: } & Multigravida & 5 & 12 \\
\hline & Primigravida & 1 & 1 \\
\hline \multirow[t]{3}{*}{ Dietary restrictions: } & No pork diet & 3 & 6 \\
\hline & Vegetarian & 2 & 3 \\
\hline & No restrictions & 1 & 4 \\
\hline \multirow[t]{4}{*}{ Occupation: } & Housewives & 6 & 9 \\
\hline & Teachers & & 2 \\
\hline & University student & & 1 \\
\hline & Assistant manager & & 1 \\
\hline \multicolumn{4}{|c|}{$\begin{array}{l}\text { Ability to communicate in English with the } \\
\text { investigator (rated as very good, good, poor, }\end{array}$} \\
\hline very poor): & Very poor & 2 & \\
\hline & Poor & 3 & 4 \\
\hline & Good & 1 & 9 \\
\hline
\end{tabular}

250HD, 25-hydroxycholecaliferol.

* For details of subjects and procedures, see p. 882. 
In the 1970s several studies were published which suggested how best to improve vitamin $\mathrm{D}$ status in Asian mothers and their newborn infants living in Britain. Heckmatt et al. (1979) supplemented forty-four Asian mothers with 1000 units (25 $\mu \mathrm{g})$ vitamin D daily 1-3 months before delivery and found that this significantly increased the plasma 25OHD concentration at delivery. Brooke et al. (1980) in a double-blind trial of vitamin D supplements in pregnant Asian women administered 1000 units $(25 \mu \mathrm{g})$ ergocalciferol/d to fifty-nine women and a placebo to sixty-seven controls during the last trimester. Mothers in the treatment group gained weight faster and at term they and their infants all had adequate plasma 25OHD concentrations; infants of the control group had larger fontanelles and five of these had symptomatic hypocalcaemia. The same workers also demonstrated improved postnatal growth in those infants whose mothers received a supplement of vitamin D (Brooke et al. 1981).

A campaign launched in Glasgow in 1979 based on educating health professionals who were in close contact with the Asian community and Asian immigrants themselves showed, in a survey carried out 2 and 3 years after the campaign, a reduction in the prevalence of rickets in children compared with the precampaign survey. The hospital discharges of Asian children with rickets also declined rapidly after the start of the campaign (Dunnigan et al. 1985). In the present study it was interesting to note that mothers with low 25OHD levels at the time of delivery had difficulty in communicating with the investigator in the English language. This is likely to indicate that they had little contact with the local community and health services which will be an additional predisposing factor to suboptimal vitamin D status.

The findings suggest that, in Cardiff, Asian women in the child-bearing age group are not being effectively targeted to improve their vitamin D status. Although the incidence of the deficiency in our study is lower than that reported in the 1970s (Heckmatt et al. 1979; Brooke et al. 1980), the findings suggest that subclinical vitamin D deficiency is still a cause for concern in this group. There is no reason to believe that these findings are not representative of other Asian communities in Britain, and in other European countries (Okonofua et al. 1987; Meulmeester et al. 1990). Therefore, more active measures should be taken to improve the vitamin D intake of the diet of Asian women during the childbearing years in order to lessen the risks of vitamin $\mathrm{D}$ deficiency and rickets occurring in early childhood and also osteomalacia in the mothers themselves.

\section{REFERENCES}

Brooke, O. G., Brown, I. R. F., Bone, C. D. M., Carter, N. D., Cleeve, H. J. W., Maxwell, J. D., Robinson, V. P. \& Winder, S. M. (1980). Vitamin D supplements in pregnant Asian women: effects on calcium status and fetal growth. British Medical Journal 280, 751-754.

Brooke, O. G., Butters, F. \& Wood, C. (1981). Intrauterine vitamin D nutrition and postnatal growth in Asian infants. British Medical Journal 283, 1024.

Brown, R. C. \& Woodhead, J.S. (1992). Measurement of circulating parathyroid hormone. In Clinical Endocrinology, pp. 527-531 [A. Grossman, editor]. Oxford: Blackwell Scientific.

Davis, O. K., Hawkins, D. S., Rubin, L. P., Posillico, J. T., Brown, E. M. \& Schiff, I. (1988). Serum parathyroid hormone (PTH) in pregnant women determined by an immunoradiometric assay for intact PTH. Journal of Clinical Endocrinology and Metabolism 67, 850-852.

Department of Health and Social Security (1980). Rickets and Osteomalacia. Report on Health and Social Subjects no. 19. London: H.M. Stationery Office.

Dunnigan, M. G., Glekin, B. M., Henderson, J. B., McIntosh, W. B., Sumner, D. \& Sutherland, G. R. (1985). Prevention of rickets in Asian children: assessment of the Glasgow Campaign. British Medical Journal 291, 239-242.

Ford, J. A., Colhoun, E. M., McIntosh, W. B. \& Dunnigan, M. G. (1972). Rickets and osteomalacia in the Glasgow Pakistani community, 1961-71. British Medical Journal 2, 677-680.

Ford, J. A., Davidson, D. C., McIntosh, W. B., Fyfe, W. M. \& Dunnigan, M. G. (1973). Neonatal rickets in Asian immigrant population. British Medical Journal 3, 211-212. 
Goel, K. M., Sweet, E. M., Logan, R. W., Warren, J. M., Arneil, G. C. \& Shanks, R. A. (1976). Florid and subclinical rickets among immigrant children in Glasgow, Lancet $\mathbf{i}, 1141-1145$.

Grindulis, H., Scott, P. H., Belton, N. R. \& Wharton, B. A. (1986). Combined deficiency of iron and vitamin D in Asian toddlers. Archives of Disease in Childhood 61, 843-848.

Heckmatt, J. Z., Peacock, M., Davies, A. E. J., McMurray, J. \& Isherwood, D. M. (1979). Plasma 25hydroxyvitamin $D$ in pregnant Asian women and their babies. Lancet ii, 546-548.

Holmes, A. M., Enoch, B. A., Taylor, J. L. \& Jones, M. E. (1973). Occult rickets and osteomalacia amongst the Asian immigrant population. Quarterly Journal of Medicine 42, 125-149.

Meulmeester, J. F., Van den Berg, H., Wedel, M., Boshius, P. G., Hulshof, K. F. \& Luyken, R. (1990). Vitamin D status, parathyroid hormone and sunlight in Turkish, Moroccan and Caucasian children in the Netherlands. European Journal of Clinical Nutrition 44, 461-470.

Okonofua, F., Menon, R. K., Houlder, S., Thomas, M., Robinson, D., O'Brien, S. \& Dandona, P. (1987). Calcium, vitamin $\mathbf{D}$ and parathyroid hormone relationships in pregnant Caucasian and Asian women and their neonates. Annals of Clinical Biochemistry 24, 22-28.

Russell, J. G. B. \& Hill, L. F. (1974). True fetal rickets. British Journal of Radiology 47, 732-734.

Stamp, T. C. B., Walker, P. G., Perry, W. \& Jenkins, M. V. (1980). Nutritional osteomalacia and late rickets in Greater London, 1974-79: clinical and metabolic studies in 45 patients. Clinics in Endocrinology and Metabolism 9, 81-105.

Turner, G., Brown, R. C., Silver, A. C., Seymour, G. \& Woodhead, J. S. (1991). Renal insufficiency and secondary hyperparathyroidism in elderly patients. Annals of Clinical Biochemistry 28, 321-326. 